\title{
Rationale for targeting VEGF, FGF, and PDGF for the treatment of NSCLC
}

This article was published in the following Dove Press journal:

OncoTargets and Therapy

28 May 2011

Number of times this article has been viewed

\author{
Marc S Ballas' \\ Abraham Chachoua ${ }^{2}$ \\ 'Department of Medicine (Cancer \\ Center), New York University Langone \\ School of Medicine, New York, NY, \\ USA; ${ }^{2}$ Department of Cardiothoracic \\ Surgery, New York University Langone \\ School of Medicine, New York, NY, USA
}

Correspondence: Marc S Ballas New York University Langone School of Medicine, 160 East 34th Street, Room 820, New York, NY 10016 , USA

$\mathrm{Tel}+\mid$ 2I2 73| 6645

Fax + $21273 \mid 5545$

Email marcballas@gmail.com
Abstract: Lung cancer remains a leading cause of death globally, with the most frequent type, nonsmall cell lung cancer (NSCLC), having a 5-year survival rate of less than $20 \%$. While platinum-based doublet chemotherapy is currently first-line therapy for advanced disease, it is associated with only modest clinical benefits at the cost of significant toxicities. In an effort to overcome these limitations, recent research has focused on targeted therapies, with recently approved agents targeting the epidermal growth factor receptor and vascular endothelial growth factor (VEGF) signaling pathways. However, these agents (gefitinib, erlotinib, and bevacizumab) provide antitumor activity for only a small proportion of patients, and patients whose tumors respond inevitably develop resistance to treatment. As angiogenesis is a crucial step in tumor growth and metastasis, antiangiogenic treatments might be expected to have antitumor activity. Important targets for the development of novel antiangiogenic therapies include VEGF, fibroblast growth factor, platelet-derived growth factor, and their receptors. It is hypothesized that targeting multiple angiogenic pathways may not only improve antitumor activity but also reduce the risk of resistance. Several novel agents, such as BIBF 1120, sorafenib, sunitinib, and cediranib have shown promising preliminary activity and tolerability in Phase II studies, and results of ongoing Phase III randomized studies will be necessary to establish the potential place of these new therapies in the management of individual patients with NSCLC.

Keywords: angiogenesis, vascular endothelial growth factor, platelet-derived growth factor, fibroblast growth factor, tyrosine kinase inhibitor, nonsmall cell lung cancer

\section{Introduction}

Lung cancer is the leading cause of cancer-related death worldwide. ${ }^{1}$ Nonsmall cell lung cancer (NSCLC) is the most frequent type of lung cancer, accounting for more than $80 \%$ of lung cancer cases. As NSCLC currently has a 5-year survival rate of less than $20 \%,{ }^{2}$ there is clearly a need for the development of more effective therapies.

Standard first-line treatment options depend on disease and patient characteristics, and may include surgery, platinum-based doublet chemotherapy, and targeted therapies. ${ }^{3}$ However, surgical resection is only a curative option if diagnosis occurs at early stage I or stage II disease (Table 1). At times, surgery with or without radiation with a more limited curative potential is an option for selected stage III NSCLC patients. Chemotherapy with a platinum-based doublet regimen is currently first-line therapy for more advanced disease, but is associated with only modest clinical benefits at the cost of significant toxicities. ${ }^{4,5}$ Furthermore, studies have shown no survival benefit and decreased quality of life with chemotherapy combinations beyond 4-6 cycles. ${ }^{6-8}$ Thus, in an effort to overcome these limitations, recent research has focused on targeted 
Table I Staging of NSCLC

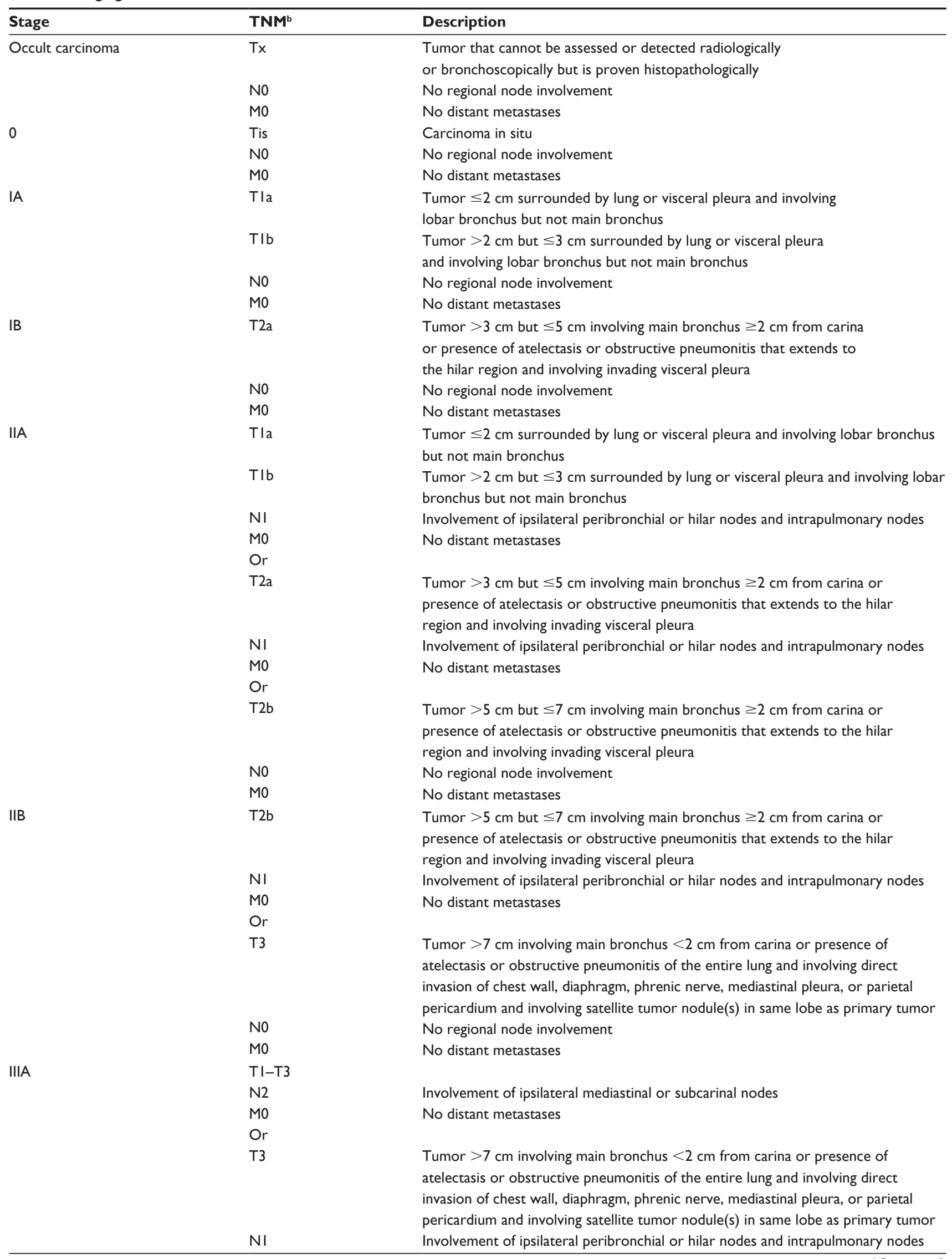


Table I (Continued)

\begin{tabular}{|c|c|c|}
\hline Stage & TNM $^{\mathbf{b}}$ & Description \\
\hline & Mo & No distant metastases \\
\hline & Or & \\
\hline & $\mathrm{T} 4$ & $\begin{array}{l}\text { Tumor any size invading the mediastinum, heart, great vessels, trachea, recurrent } \\
\text { laryngeal nerve, esophagus, vertebral body, or carina; or tumor with satellite tumor } \\
\text { nodule(s) in a different lobe, ipsilateral to that of the primary tumor }\end{array}$ \\
\hline & $\mathrm{N} 0-\mathrm{NI}$ & $\begin{array}{l}\text { No regional node involvement or involvement of ipsilateral peribronchial or hilar } \\
\text { nodes and intrapulmonary nodes }\end{array}$ \\
\hline & Mo & No distant metastases \\
\hline \multirow[t]{7}{*}{ IIIB } & TI-T4 & \\
\hline & N3 & $\begin{array}{l}\text { Involvement of contralateral mediastinal or hilar nodes and ipsilateral or } \\
\text { contralateral scalene or supraclavicular nodes }\end{array}$ \\
\hline & Mo & No distant metastases \\
\hline & Or & \\
\hline & $\mathrm{T} 4$ & $\begin{array}{l}\text { Tumor any size invading the mediastinum, heart, great vessels, trachea, recurrent } \\
\text { laryngeal nerve, esophagus, vertebral body, or carina; or tumor with satellite } \\
\text { tumor nodule(s) in a different lobe, ipsilateral to that of the primary tumor }\end{array}$ \\
\hline & N2 & Involvement of ipsilateral mediastinal or subcarinal nodes \\
\hline & Mo & No distant metastases \\
\hline \multirow[t]{4}{*}{ IV } & $\mathrm{Tx}-\mathrm{T} 4$ & Any $\mathrm{T}$ \\
\hline & $\mathrm{N} x-\mathrm{N}^{\mathrm{c}}$ & Any $N$ \\
\hline & Mla & $\begin{array}{l}\text { Satellite tumor nodule(s) in contralateral lobe to that of primary tumor or tumors } \\
\text { with malignant pleural or pericardial effusion }\end{array}$ \\
\hline & MIb & Distant metastases \\
\hline
\end{tabular}

Notes: ${ }^{\text {Based }}$ on the Seventh Edition of TNM Staging of Lung Tumors; however, trials referred to in this review article have followed either the current or previous staging

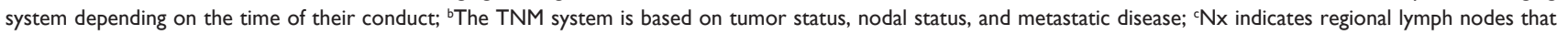
cannot be assessed.

Copyright (C) 201 I. Adapted with permission from the American College of Chest Physicians. Lababede O, Meziane M, Rice T. Seventh edition of the cancer staging manual and stage grouping of lung cancer: quick reference chart and diagrams. Chest. 20II;139(I):183-189.114

Abbreviations: NSCLC, nonsmall cell lung cancer; TNM, tumor node metastasis.

therapies that may more selectively inhibit tumor cell growth while minimizing toxicity to healthy cells and tissue.

\section{Currently available targeted agents for NSCLC}

Currently approved targeted agents in NSCLC are limited to inhibition of the epidermal growth factor receptor (EGFR) $)^{9,10}$ and vascular endothelial growth factor (VEGF) signaling pathways. ${ }^{11}$ The EGFR family of receptor tyrosine kinases serve as mediators of cell signaling by extracellular growth factors, with binding of their ligands activating intracellular pathways that promote tumor growth and survival. ${ }^{12}$ An activating mutation in EGFR is observed in approximately $10 \%$ of unselected Western lung cancer patients and in a higher percentage of certain NSCLC subgroups, such as nonsmokers and those of Asian ethnicity. ${ }^{12}$ Reversible EGFR-targeting tyrosine kinase inhibitors such as gefitinib (Iressa ${ }^{\circledR}$; AstraZeneca; Wilmington, DE) and erlotinib (Tarceva ${ }^{\circledR}$; Genentech; South San Francisco, CA) inhibit EGFR signaling.

Initial Phase II results with gefitinib led to approval by the United States Food and Drug Administration (FDA) of this agent for NSCLC. These results showed overall objective response rates (ORR) of 19\% (95\% confidence interval [CI],
11.5-27.3) among 105 patients with stage III/IV NSCLC receiving a dose of $500 \mathrm{mg} /$ day and $18.4 \%$ (95\% CI, 12.1-27.9) of 103 patients receiving $250 \mathrm{mg}$ /day in one study and $10.6 \%(95 \% \mathrm{CI}, 6.0-16.8)$ with both doses in another study. ${ }^{13,14}$ However, addition of gefitinib to standard chemotherapy failed to prolong overall survival (OS) compared with chemotherapy alone in subsequent Phase III trials. ${ }^{15-17}$ Based on more recent Phase III data in which OS with gefitinib was noninferior or not significantly different to that obtained with docetaxel, a taxane, ${ }^{18}$ in patients with advanced or metastatic NSCLC who had been pretreated with platinum-based chemotherapy, ${ }^{19,20}$ the United States restricted treatment with gefitinib to patients who have previously benefited from it. ${ }^{10}$ However, in the European Union and Asia, gefitinib remains in use for NSCLC patients with EGFR-activating mutations. ${ }^{21}$

Erlotinib was approved in the United States in 2004 for the treatment of patients with locally advanced or metastatic NSCLC whose disease has progressed following at least one chemotherapy regimen ${ }^{3,22}$ based on prolongation of OS (6.7 versus 4.7 months for placebo; hazard ratio (HR), 0.70; $95 \%$ CI, 0.58-0.85; $P<0.001)$ in a double-blind Phase III trial, BR21, involving 731 patients with stage IIIB/IV NSCLC. ${ }^{23}$ 
Erlotinib was also recently approved for maintenance therapy in patients with locally advanced or metastatic NSCLC whose disease has not progressed after 4 cycles of platinum-based therapy, ${ }^{24}$ based on the SATURN trial. The SATURN Phase III trial $(\mathrm{N}=884)$ showed erlotinib prolonged progressionfree survival (PFS) versus placebo irrespective of $E G F R$ mutation status (12.3 versus 11.1 weeks; HR, $0.71 ; 95 \% \mathrm{CI}$, $0.62-0.82 ; P<0.0001){ }^{25}$

Response rates in the gefitinib and erlotinib Phase III studies that were conducted in nonselected populations were typically around $10 \%$, meaning that for many patients, their tumors fail to respond to these agents. ${ }^{26-28}$ Those who do respond to treatment eventually develop resistance to EGFR tyrosine kinase inhibitors, due either to a secondary mutation in the EGFR gene or amplification of mesenchymal-epithelial transition factor (MET), another receptor tyrosine kinase..$^{12,29}$

The VEGF pathway controls angiogenesis, a necessary step in tumor growth, metastasis, and malignancy. ${ }^{30}$ Formation of new vasculature is required for larger tumors to obtain nutrients and oxygen; otherwise, nutrient supply is limited by diffusion, slowing tumor growth. ${ }^{31}$ Indeed, tumor vascularization is a prognostic indicator of disease progression in various cancers, including NSCLC. ${ }^{32-34}$ Thus, as tumor growth is dependent on developing and maintaining this blood supply, antiangiogenic treatments might be expected to have antitumor activity.

Bevacizumab (Avastin ${ }^{\circledR}$, Genentech) is a monoclonal antibody directed against VEGF that is currently approved in combination with carboplatin, a platinum agent, and paclitaxel, a taxane, as first-line treatment of unresected, locally advanced, recurrent or metastatic nonsquamous NSCLC. ${ }^{35}$ Bevacizumab is only available for patients whose tumors have nonsquamous histology and is not recommended for patients with hemorrhage or recent hemoptysis. ${ }^{11,36,37}$ These exclusions are based on evidence from Phase II and III clinical trials. An early Phase II study randomized 99 patients with advanced (stage IIIB/IV or recurrent) NSCLC to receive bevacizumab $7.5 \mathrm{mg} / \mathrm{kg}$ or $15 \mathrm{mg} / \mathrm{kg}$ plus carboplatin and paclitaxel or chemotherapy alone. ${ }^{36}$ Bevacizumab $15 \mathrm{mg} / \mathrm{kg}$ significantly prolonged time to disease progression (TTP) (7.4 versus 4.2 months with chemotherapy alone; HR, $0.57 ; P=0.023)$ and provided a higher response rate $(31.5 \%$ of 34 patients versus $18.8 \%$ of 32 patients) and a modestly increased median OS (17.7 versus 14.9 months; $P=0.63$ ). With the lower dose of bevacizumab, TTP was 4.3 months, ORR was $28.1 \%$ of 32 patients, and OS was 11.6 months. However, fatal hemoptysis was observed in 4 of 66 patients $(6 \%)$ receiving bevacizumab. The study also correlated squamous histology with an increased risk of serious pulmonary hemorrhage, as four out of six cases of life-threatening bleeding occurred in patients with squamous carcinomas. ${ }^{36}$

The Phase III Eastern Cooperative Oncology Group (ECOG) 4599 trial $^{38}$ evaluated bevacizumab $15 \mathrm{mg} / \mathrm{kg}$ in combination with carboplatin and paclitaxel in 878 chemotherapy-naive patients. Patients with squamous histology, brain metastases, inadequate organ function, clinically significant hemoptysis, or ECOG performance status $>1$ were excluded. The ORR was higher with bevacizumab (133 out of 381 patients, 35\%) compared with carboplatin and paclitaxel alone (59 out of 392 patients, $15 \% ; P<0.001)$. The addition of bevacizumab also prolonged median OS (12.3 versus 10.3 months; HR, $0.80 ; P=0.003)$ and PFS (6.2 versus 4.5 months; HR, 0.66; $P<0.001)$ compared with chemotherapy alone. Grade $\geq 3$ (lowest possible grade of an adverse event is 1 [mild adverse event] and highest possible grade is 5 [death]) bleeding events were reported in 19 out of 427 patients receiving bevacizumab plus chemotherapy $(4.4 \%)$, while eight patients $(1.9 \%)$ experienced hemoptysis. ${ }^{38}$ Fifteen treatment-related deaths were observed in the bevacizumab arm compared with two deaths in the carboplatin plus paclitaxel alone $\operatorname{arm}(P<0.001)$, five of which were caused by hemorrhage. Evaluable patients receiving bevacizumab plus carboplatin and paclitaxel $(n=427)$ experienced higher rates of grade 4 neutropenia $(25.5 \%$ versus $16.8 \%$ in 440 patients receiving carboplatin and paclitaxel alone; $P=0.002)$ and thrombocytopenia $(1.6 \%$ versus $0.2 \%$; $P=0.04)$ as well as grade 3 febrile neutropenia (4\% versus $1.8 \% ; P=0.02)$, grade $3-4$ hyponatremia $(3.5 \%$ versus $1.1 \% ; P=0.02)$, grade $3-4$ hypertension $(6.8 \%$ versus $0.5 \%$; $P<0.001)$, grade 3 headache $(0.5 \%$ versus $3 \% ; P=0.003)$, grade 3 rash $(2.3 \%$ versus $0.5 \% ; P=0.02)$, and grade $\geq 3$ bleeding events $(0.7 \%$ versus $4.4 \% ; P<0.001) .{ }^{38}$

In the similarly designed Phase III AVAiL trial, first-line treatment with bevacizumab 7.5 or $15 \mathrm{mg} / \mathrm{kg}$ in combination with cisplatin and gemcitabine versus cisplatin and gemcitabine alone was evaluated in 1043 patients with recurrent or advanced NSCLC. ${ }^{39}$ Bevacizumab prolonged PFS at both $7.5 \mathrm{mg} / \mathrm{kg}$ (6.7 versus 6.1 months for placebo; $\mathrm{HR}, 0.75 ; P=0.003)$ and $15 \mathrm{mg} / \mathrm{kg}$ (6.5 months; HR, 0.82; $P=0.03$ versus placebo), ${ }^{39}$ but OS was not significantly different, possibly due to the high use of post-study secondline treatments. ${ }^{40}$ The incidence of pulmonary hemorrhage was only $1.5 \%$ with bevacizumab $7.5 \mathrm{mg} /$ day (5 out of 330 patients) and $0.9 \%$ with bevacizumab $15 \mathrm{mg} / \mathrm{kg}$ ( 3 out of 329 patients). ${ }^{39}$ The rates of grade $\geq 3$ hypertension, vomiting, neutropenia, and bleeding were numerically higher in patients who received bevacizumab than in patients who did not. 
Another Phase III trial, the ATLAS study, compared bevacizumab $15 \mathrm{mg} / \mathrm{kg}$ plus erlotinib with bevacizumab alone as a maintenance therapy after 4 cycles of combined treatment with bevacizumab and platinum-based doublet chemotherapy in 768 patients with advanced NSCLC.41 Patients with treated brain metastases and peripheral or extrathoracic squamous tumors were allowed to participate in this study. Preliminary efficacy results showed that the combination of erlotinib plus bevacizumab increased PFS (4.8 versus 3.7 months for bevacizumab alone; HR, 0.72; 95\% CI, 0.59-0.88; $P=0.0012$ ) but did not significantly prolong OS (15.9 versus 13.9 months; HR, $0.90 ; P=0.2686$ ). Safety data $(n=598)$ have been reported for the initial chemotherapy phase of the trial. ${ }^{42}$ The most common grade $\geq 3$ adverse event was hypertension, reported for 13 out of 303 patients receiving bevacizumab with carboplatin and paclitaxel (4.3\%), 9 out of 183 patients receiving bevacizumab with carboplatin and gemcitabine (4.9\%), and 3 out of 112 receiving carboplatin plus docetaxel $(2.7 \%)$. Grade $\geq 2$ pulmonary or central nervous system hemorrhage each occurred in less than $2 \%$ of patients, as did grade $\geq 3$ gastrointestinal perforations. Overall hemorrhage rates (all grades) were reported for seven patients $(2.3 \%)$ with bevacizumab plus carboplatin and paclitaxel, nine patients (4.9\%) with bevacizumab plus carboplatin and gemcitabine, and nine patients (8\%) with carboplatin plus docetaxel.

The Phase II BRIDGE study examined whether paclitaxel and carboplatin in combination with delayed bevacizumab administration would improve tolerability in patients with previously untreated squamous NSCLC; out of 31 patients treated with bevacizumab, one patient (3.2\%) experienced a grade 3 pulmonary hemorrhage..$^{43}$ Ongoing follow-up Phase II and III trials are currently evaluating bevacizumab therapy in combination with other targeted agents as well as standard chemotherapy in both first-line and second-line settings for multiple malignancies, including NSCLC..$^{40,44-47}$ While bevacizumab is the only antiangiogenic therapy currently approved for NSCLC, there are several other compounds currently in clinical development, including monoclonal antibodies to VEGF and inhibitors of the intracellular tyrosine kinase domain of the VEGF receptor, as described later in this review. Because of the issues of resistance and eligibility associated with currently approved targeted agents in NSCLC, there is a critical need for improved therapies. The subsequent sections of this review highlight important antiangiogenic targets as well as emerging clinical data regarding novel antiangiogenic compounds for NSCLC treatment.

\section{Rationale for targeting angiogenic pathways in NSCLC \\ VEGF signaling}

Important proangiogenic targets for the development of antiangiogenic therapies include VEGF, fibroblast growth factor (FGF), and platelet-derived growth factor (PDGF), along with their corresponding receptors (VEGFR, FGFR, and PDGFR, respectively). The VEGF-related family of proangiogenic signaling factors comprises VEGF-A (commonly referred to as VEGF), VEGF-B, VEGF-C, VEGF-D, VEGF-E, and placental growth factor (PIGF). ${ }^{48}$ In addition to tumor angiogenesis, VEGF signaling mediates several other pathological conditions including inflammatory disorders, female reproductive processes, and intraocular neovascularization syndromes. ${ }^{49}$ The VEGF ligands mediate their angiogenic effects via three receptor tyrosine kinases: VEGFR-1 (also known as fms-like tyrosine kinase 1 [flt-1]), VEGFR-2 (also known as kinase-insert domain receptor [KDR]), and VEGFR-3 (flt-4). The primary receptor for VEGF is VEGFR-2. ${ }^{49}$ Binding of VEGF to its receptors causes receptor dimerization, autophosphorylation, and downstream signaling through a variety of pathways, including phosphoinositide (PI)-3 kinase (PI3K), v-src sarcoma viral oncogene homolog ( $\mathrm{Src}$ ), and phospholipase-C $\gamma$ (PLC $\gamma)$, which can activate proliferation and migratory pathways driving angiogenesis (Figure 1).$^{49}$ Neuropilin-1 and neuropilin-2, members of the neuropilin family of receptors, are expressed on endothelial cells and may be activated by VEGF, dimerize with VEGFR-1 and -2, and activate downstream signaling: ${ }^{50}$ inhibitors of neuropilin-VEGF interaction are undergoing preclinical evaluation for the treatment of cancer. ${ }^{51,52}$ In animal tumor models, VEGF is produced both by tumor cells and also by stromal tissue, ${ }^{53,54}$ although stromal expression of VEGF was not observed in a study of NSCLC samples from patients..$^{55}$ Upregulation of VEGF and VEGFR have been observed in NSCLC tumor samples, with expression correlated with tumor angiogenesis, shorter postoperative recurrence time, and shorter survival time. ${ }^{55}$ A meta-analysis of NSCLC studies has also suggested that VEGF expression is an unfavorable prognostic factor for survival (HR, $1.48 ; 95 \% \mathrm{CI}, 1.27-1.72){ }^{56}$

\section{FGF signaling}

The FGF family comprises 22 ligands that have a diverse array of biological functions. For example, FGF signaling plays a role in fetal development; mutations in FGFR1 are associated with bone disorders, and mutations in FGFR2 are known to cause various craniosynostosis syndromes 


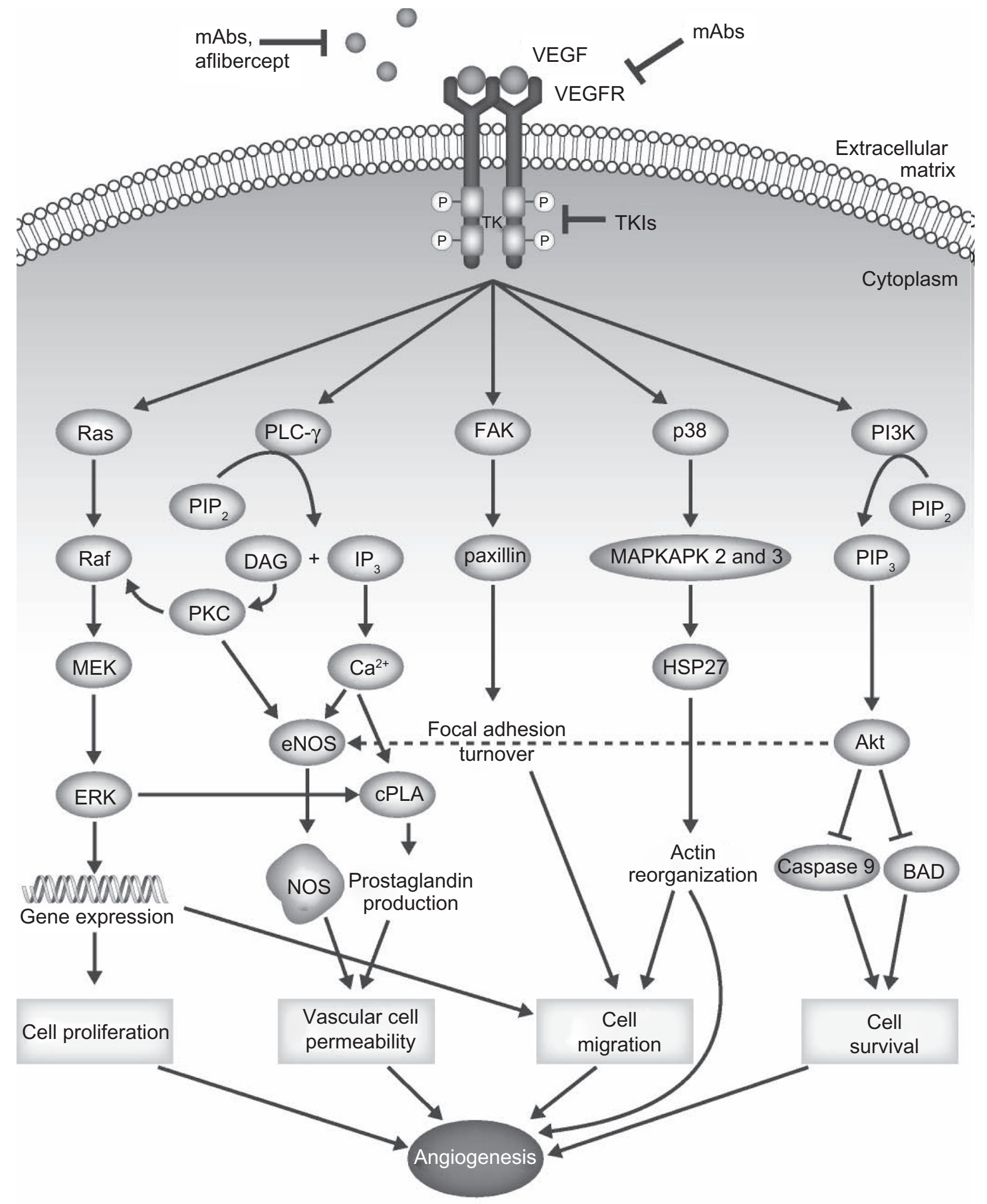

Figure I Connections between VEGF/VEGFR signaling and angiogenic processes. Depiction of the role of VEGFR signaling in tumor angiogenesis. Adapted by permission from MacMillan Publishers Ltd: Nat Rev Clin Oncol, ${ }^{13}$ copyright 2009.

Abbreviations: Akt, protein kinase B; BAD, Bcl-2-associated death promoter; cPLA, cytoplasmic phospholipase A; DAG, diacyl-glycerol; eNOS, endothelial nitric oxide synthase; ERK, extracellular signal-regulated kinase; FAK, focal adhesion kinase; HSP, heat shock protein; IP, inositol trisphosphate; mAbs, monoclonal antibodies; MAPKAPK, mitogen-activated protein kinase-actived protein kinase; MEK, mitogen-activated protein kinase kinase; NOS, nitrous oxide synthase; PI3K, phosphatidylinositol 3-kinase; PIP $_{2}$, phosphatidylinositol 4,5bisphosphate; PIP, phosphatidylinositol 3,4,5-trisphosphate; PKC, protein kinase C; PLC, phospholipase C; Raf, v-raf I murine leukemia viral oncogene homolog I; Ras, retrovirusassociated DNA sequences; TKIs, tyrosine kinase inhibitors; VEGF, vascular endothelial growth factor; VEGFR, vascular endothelial growth factor receptor. 
(premature closure of sutures in the fetal skull before completion of brain growth). ${ }^{57}$ FGF-1, FGF-2, FGF-4, FGF-5, and FGF-8 have been associated with angiogenesis. ${ }^{58}$ Two FGF receptor tyrosine kinases, FGFR-1 and FGFR-2, are expressed in endothelial cells and can activate signaling pathways involved in tumor angiogenesis including the PI3K and mitogen-activated protein kinase (MEK)-extracellular signal-regulated kinase kinase (ERK) pathways, ${ }^{58}$ resulting in endothelial cell activation and recruitment of pericytes, vascular smooth muscle cells, and monocytes. ${ }^{58,59}$ FGF also regulates expression of proteases, integrins, and cadherins involved in reorganization of the extracellular matrix..$^{60,61}$ In this way, FGF signaling affects vascular integrity, an important component of the vascular remodeling required for angiogenesis. ${ }^{62}$ In addition, cross-talk between FGFs, VEGFs, and inflammatory cytokines and chemokines may play a role in the modulation of blood vessel growth in various pathological conditions, including tumors. ${ }^{58}$

\section{PDGF signaling}

PDGF ligands are released from platelets upon vascular damage. ${ }^{63}$ There are five dimeric PDGF ligands, PDGF-AA, -BB, -CC, -DD, and $-\mathrm{AB}$, and two receptor tyrosine kinases, PDGFR- $\alpha$ and PDGFR- $\beta$, which mediate downstream effects through some of the same pathways activated by VEGFR (Figure 1). ${ }^{64}$ These receptors are expressed on endothelial cells, pericytes, and vascular smooth muscle cells, ${ }^{63}$ which aid in development of tumor microvessels. Release of PDGF-BB by endothelial cells recruits pericytes and vascular muscle cells, which, in turn, control vascular integrity, development, and stabilization. ${ }^{65-67}$ In a preclinical chorioallantoic membrane (CAM) model involving chick eggs, PDGF-AA, -AB, and -BB induced development of new blood vessels, while in another model, PDGF-BB but not -AA stimulated the migration of rat brain capillary endothelial cells. ${ }^{68,69}$ Enhanced PDGF signaling has been associated with tumorigenesis and angiogenesis, as well as other pathological events such as atherosclerosis and re-stenosis of vessels after balloon angiography and coronary artery bypass grafting. ${ }^{70}$ In addition, PDGF inhibition may be a rational strategy for treatment of fibrotic liver disease, pulmonary fibrosis, and the development of proliferative vitreoretinopathy. ${ }^{70}$

The rationale for targeting the above signaling pathways arose from preclinical models, in which inhibition of VEGF/ VEGFR, FGF/FGFR, or PDGF/PDGFR signaling resulted in reduced angiogenesis and impaired tumor proliferation. For example, treatment with a VEGF monoclonal antibody inhibited the growth of tumor cell lines that had been injected into nude mice, but did not affect the growth rate of the same cell lines in vitro, supporting the explanation that treatment was acting against angiogenesis rather than directly against tumor cells. ${ }^{71,72}$ Furthermore, activation of PDGF and FGF pathways has been implicated in the development of resistance to VEGF inhibition. In a mouse model of pancreatic cancer, relapse after treatment with an anti-VEGF monoclonal antibody was associated with tumor revascularization secondary to hypoxia-mediated induction of other proangiogenic factors, including increased FGF-2 expression. ${ }^{73}$ Upon combination treatment with both VEGF and FGF inhibitors, tumor revascularization and growth were reduced. ${ }^{73}$ Likewise, expression of PDGFR has also been associated with resistance to VEGF-targeted therapy in the mouse pancreatic cancer model, with combined targeting of VEGF and PDGF signaling producing regression of established tumor blood vessels and inhibiting tumor growth. ${ }^{74,75}$ In fact, the VEGF, PDGF, and FGF signaling pathways appear to be highly integrated, suggesting that compensation and/or synergism between pathways occurs in angiogenesis. ${ }^{76,77}$ Thus, targeting multiple receptor tyrosine kinases may be required for effective antiangiogenic therapies.

In the clinical development of antiangiogenic therapies, two approaches have been used (Table 2); the first has been to inhibit ligand binding and receptor activation using targeted antibodies, while the second has been to inhibit receptor activation using tyrosine kinase inhibitors targeting VEGFR, FGFR, and/or PDGFR. Results of Phase II and Phase III clinical trials of agents discussed in this review in NSCLC are summarized in Table 3.

\section{Investigational antiangiogenic agents for NSCLC Investigational therapeutic antibodies}

Ramucirumab (IMC-1121B; ImClone Systems Inc, New York, NY) is a human monoclonal anti-VEGFR-2 antibody. In a Phase I study in which 37 patients with advanced solid malignancies were given escalating doses of ramucirumab, four patients $(15 \%)$ had a partial response, and 11 patients (30\%) exhibited a response or stable disease lasting 6 months or longer. ${ }^{78}$ The most common serious adverse events included hypertension (13.5\%), abdominal pain $(10.8 \%)$, anorexia, vomiting, alkaline phosphatase increases, headache, proteinuria, dyspnea, and deep vein thrombosis (each in $5.4 \%$ of patients). A dosage of $13 \mathrm{mg} / \mathrm{kg}$ was considered the maximum-tolerated dose in this study, 
Table 2 Approved and emerging antiangiogenic therapies for NSCLC

\begin{tabular}{|c|c|c|c|}
\hline Agent & Type & Target(s) & $\begin{array}{l}\text { Current phase of clinical } \\
\text { development }\end{array}$ \\
\hline Bevacizumab"I & Monoclonal antibody & VEGF & Approved for NSCLC \\
\hline Ramucirumab $^{78}$ & Monoclonal antibody & VEGFR-2 & Phase III \\
\hline Aflibercept ${ }^{\prime \prime \prime}$ & Fusion protein & VEGF & Phase III \\
\hline $\mathrm{BIBF} \mid \mathrm{I} 20^{80}$ & TKI & VEGFR-I, $-2,-3$, PDGFR- $\alpha / \beta$, FGFR-I, $-2,-3$, Src, flt-3 & Phase III \\
\hline Sorafenib ${ }^{87}$ & TKI & VEGFR-2, -3 , PDGFR- $\beta$, Raf, flt-3, c-kit & Phase III \\
\hline Sunitinib ${ }^{92}$ & TKI & VEGFR-I, $-2,-3$, PDGFR- $\alpha / \beta$, c-kit, flt-3, RET & Phase III \\
\hline Cediranib ${ }^{96}$ & TKI & VEGFR-I, $-2,-3$, PDGFR- $\beta$, FGFR-I, c-kit & Phase III \\
\hline Motesanib 102 & TKI & VEGFR-I, $-2,-3$, PDGFR- $\beta$, c-kit, RET & Phase III \\
\hline Pazopanib 107 & TKI & VEGFR-I, $-2,-3$, PDGFR- $\alpha / \beta$, FGFR-I, -3, c-kit & Phase III \\
\hline Axitinib 109 & TKI & VEGFR-I, $-2,-3$, PDGFR- $\beta$ & Phase II \\
\hline ABT-869100 & TKI & VEGFR-I, $-2,-3$, PDGFR- $\beta$ & Phase II \\
\hline
\end{tabular}

Abbreviations: c-kit, stem cell factor receptor; FGFR, fibroblast growth factor receptor; flt-3, fms-like tyrosine kinase 3; NSCLC, nonsmall cell lung cancer; PDGFR, platelet-derived growth factor receptor; Raf, v-raf I murine leukemia viral oncogene homolog I; RET, rearranged during transfection receptor; Src, v-src sarcoma viral oncogene homolog; TKI, tyrosine kinase inhibitor; VEGF, vascular endothelial growth factor; VEGFR, vascular endothelial growth factor receptor.

as two patients given the higher dose of $16 \mathrm{mg} / \mathrm{kg}$ experienced dose-limiting hypertension and deep venous thrombosis, respectively. Although none of the patients in this Phase I study had NSCLC, the findings provided the rationale for Phase II investigation of ramucirumab in this condition. A Phase II study is currently examining ramucirumab combined with paclitaxel and carboplatin as a first-line treatment for patients with NSCLC, including those with squamous histology or brain metastases, with a planned enrollment of approximately 40 patients. ${ }^{79}$ Preliminary results from 15 patients demonstrated an ORR of 67\% (10 patients) with one complete response and a median PFS of 6 months. Two patients experienced serious adverse events (grade 2 pneumothorax and grade 4 febrile neutropenia), and one additional patient withdrew from the study due to pneumothorax. ${ }^{79}$

\section{Investigational receptor tyrosine kinase inhibitors}

Given the multitude of intracellular signaling pathways that influence tumorigenesis, a number of potential advantages may exist with agents that inhibit multiple targets simultaneously. For example, this approach may prevent the development of resistance to antitumor agents. In addition, using a multitargeted approach, multiple tumorigenic pathways (such as angiogenesis and cell survival) may be inhibited and so maximize antitumor activity.

BIBF 1120 (Boehringer Ingelheim, Ingelheim, Germany) is an orally available multitargeted TKI that inhibits signaling through VEGFR-1, -2 , and -3, PDGFR- $\alpha / \beta$, and FGFR-1, -2, and -3 as well as Src and flt-3. ${ }^{80,81}$ In preclinical models, including human tumor xenografts in nude mice and rat tumor models, BIBF 1120 reduced tumor vessel density and integrity, resulting in inhibition of tumor growth. ${ }^{80}$ In Phase I studies, the most common drug-related adverse events observed with BIBF 1120 were reversible serum liver enzyme elevations and mild fatigue. ${ }^{82-84}$ When BIBF 1120 was combined with pemetrexed, a folate antimetabolite, ${ }^{18}$ stable disease was achieved in 13 out of 26 patients (50\%) with recurrent advanced NSCLC who had previously received one prior platinum-based chemotherapy regimen. ${ }^{84}$ In this study, grade 3 fatigue was reported by six patients (23\%), and grade 3 increases in alanine transaminase (ALT) were observed in three patients (11\%). In Phase I studies of BIBF 1120 monotherapy in patients with advanced solid tumors, the first study $(\mathrm{N}=61)$ observed grade 3 liver enzyme elevations in three patients receiving once-daily dosing with BIBF 1120 and no patients receiving twice daily dosing, ${ }^{82}$ while the second study $(\mathrm{N}=21)$ showed grade 3 elevations of ALT and $\gamma$-glutamyl transpeptidase $(\gamma$-GT) in six patients each and grade 3 elevation of aspartate aminotransferase (AST) in three patients. ${ }^{83}$

A Phase II trial tested BIBF 1120 monotherapy in 73 patients with relapsed NSCLC for which one or two lines of chemotherapy had previously failed and who had an ECOG performance status of $0-2 .{ }^{85}$ Patients were assigned one of two doses: $150 \mathrm{mg}(\mathrm{n}=37)$ or $250 \mathrm{mg}(\mathrm{n}=36)$ twice daily. For all patients, median OS was 21.9 weeks, and median PFS was 6.9 weeks; one patient exhibited a partial response, and $48 \%$ of patients exhibited stable disease. Patients with an ECOG performance status of $0-1(n=56)$ exhibited a median PFS of 11.6 weeks and a median OS of 37.7 weeks. Grade 3 and 4 toxicities included ALT elevations (9.6\%), diarrhea $(8.2 \%)$, nausea $(6.8 \%)$, $\gamma$-GT elevations $(4.1 \%)$, abdominal pain $(2.7 \%)$, vomiting $(2.7 \%)$, anorexia $(1.4 \%)$, AST 
elevations (1.4\%), and fatigue (1.4\%). Phase III trials are currently testing BIBF 1120 in combination with docetaxel in the LUME-Lung 1 study (NCT00805194) and pemetrexed in the LUME-Lung 2 study (NCT00806819). Of note, the LUME-Lung 2 study only includes patients with NSCLC of nonsquamous histology to conform with the FDA-approved indication of pemetrexed. ${ }^{86}$

Other small molecule multitargeted tyrosine kinase inhibitors are currently in clinical development. Sorafenib (Bay 43-9006; Nexavar ${ }^{\circledR}$, Bayer, Leverkusen, Germany) targets tumor cell growth and angiogenesis by inhibiting signaling through VEGFR-2 and -3, PDGFR- $\beta$, v-raf 1 murine leukemia viral oncogene homolog 1(Raf), flt-3, and stem cell factor receptor (c-kit).$^{87}$ In a Phase II study of singleagent sorafenib in 51 patients with relapsed or refractory advanced nonsquamous NSCLC, there were no responses, but 30 patients (59\%) exhibited stable disease. ${ }^{88}$ Median PFS was 2.7 months, while median OS was 6.7 months. The most common grade 3 and 4 adverse events included hypertension in two patients (4\%) and hand-foot skin disease in five patients (10\%). In a larger Phase II study involving 342 patients with pretreated NSCLC and no evidence of brain metastases, patients were treated with sorafenib for two cycles; patients who responded continued on sorafenib for the second stage of the study, patients with stable disease were randomized to sorafenib or placebo, and those with progression discontinued. Preliminary results from the 97 patients randomized in stage 2 of the study show that sorafenib treatment prolonged PFS to 3.6 months compared with 1.9 months with placebo $(P=0.01)$ and resulted in stable disease for 16 patients (29\%) compared with two patients with placebo $(5 \% ; P=0.002) .{ }^{89}$ The most common grade 3 or 4 adverse events were rash or hand-foot syndrome (15\%) and fatigue (11\%). Two patients receiving sorafenib in the first stage of the study and one patient in the second stage experienced grade $\geq 3$ hemoptysis.

The Phase III ESCAPE trial evaluated sorafenib in combination with carboplatin plus paclitaxel in 926 patients with advanced untreated nonsquamous or squamous NSCLC, ${ }^{90}$ but the study was halted when an interim analysis showed median OS was 10.7 months with sorafenib plus chemotherapy and 10.6 months with chemotherapy alone (HR, 1.15; 95\% CI, $0.94-1.41 ; P=0.915)$. Likewise, there was no significant difference between treatments in PFS (4.6 versus 5.4 months, respectively; HR, $0.99,95 \% \mathrm{CI}, 0.84-1.16$; $P=0.433$ ) or ORR (27.4\% versus $24.0 \% ; P=0.1015)$. Among patients with squamous histology, those receiving sorafenib $(\mathrm{n}=109)$ had a lower OS (8.9 versus 13.7 months; HR, 1.85; 95\%
CI, 1.22-2.81) and PFS (4.3 versus 5.8 months; HR, 1.31; 95\% CI, 0.94-1.83) compared with patients receiving chemotherapy alone $(n=114)$, whereas patients with other nonsquamous histologies had similar OS and PFS in the two treatment groups. The most common sorafenib-related grade $\geq 3$ adverse events in all patients included rash (8\%), hand-foot skin reaction ( $8 \%)$, and diarrhea (4\%). The histological subtype of NSCLC did not appear to affect the overall tolerability of treatment; patients receiving sorafenib plus chemotherapy with nonsquamous versus squamous histologies had similar rates of drug-related adverse events occurring at all grades (77\% versus $87 \%$ ), grade $3(26 \%$ versus $33 \%$ ), and grade 4 ( $9 \%$ versus $9 \%$ ), respectively. However, four out of six fatal hemorrhagic or bleeding events observed in this study (four with sorafenib and two with chemotherapy alone) occurred in patients with squamous histology (two in each arm).${ }^{90}$ The results of the ESCAPE study led to the exclusion of patients with squamous histology from the subsequent NExUS trial, which aimed to compare first-line treatment with sorafenib in combination with gemcitabine and cisplatin versus gemcitabine and cisplatin alone in a planned 900 patients with advanced NSCLC (NCT00449033). However, the NExUS trial was also halted because it did not meet the primary endpoint for improving OS. ${ }^{91}$

Sunitinib (SU11248; Sutent ${ }^{\circledR}$, Pfizer; New London, CT) targets signaling through VEGFR-1, -2 , and -3 , PDGFR- $\alpha / \beta$, rearranged during transfection (RET), as well as c-kit and flt-3. ${ }^{92}$ Sunitinib single-agent therapy was investigated in a Phase II trial of 63 patients with advanced NSCLC that had progressed after platinum-based chemotherapy. ${ }^{93}$ Patients were excluded from this study if they had experienced a grade 3 hemorrhage or hemoptysis within 4 weeks before the start of the treatment; additionally, patients who had received prior antiangiogenic therapy were excluded. Seven patients achieved a partial response with sunitinib, resulting in an ORR of $11.1 \%$ (95\% CI, 4.6-21.6), while 18 patients (28.6\%) exhibited stable disease for $\geq 8$ weeks. Median PFS was 12 weeks (95\% CI, 10.0-16.1), median OS was 23.4 weeks (95\% CI, 17.0-28.3), and the 1-year survival rate was $20.2 \%(95 \% \mathrm{CI}, 10.0 \%-30.4 \%)$. The most common grade $\geq 3$ adverse events were fatigue or asthenia in 18 patients $(29 \%)$, lymphopenia in 15 patients $(25 \%)$, pain or myalgia in 11 patients (14\%), and dyspnea in seven patients (11\%). Another second-line Phase II study of 47 patients with advanced NSCLC that had been treated with at least two chemotherapy regimens reported a partial response in one patient, giving an ORR of $2.1 \%(95 \%$ CI, $0.1-11.3)$, with 11 patients $(23.4 \%)$ exhibiting stable disease for $\geq 8$ weeks. ${ }^{94}$ 


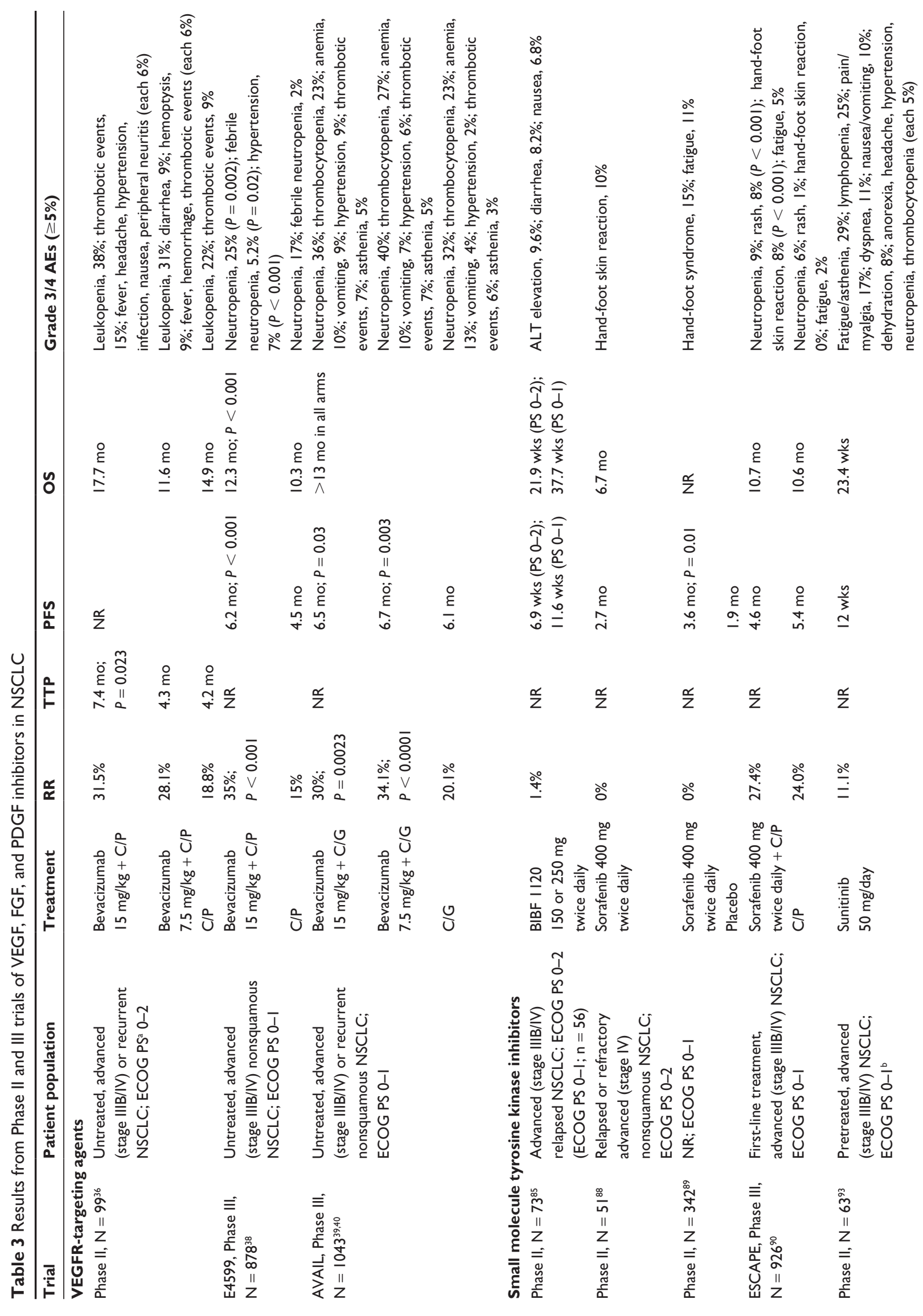




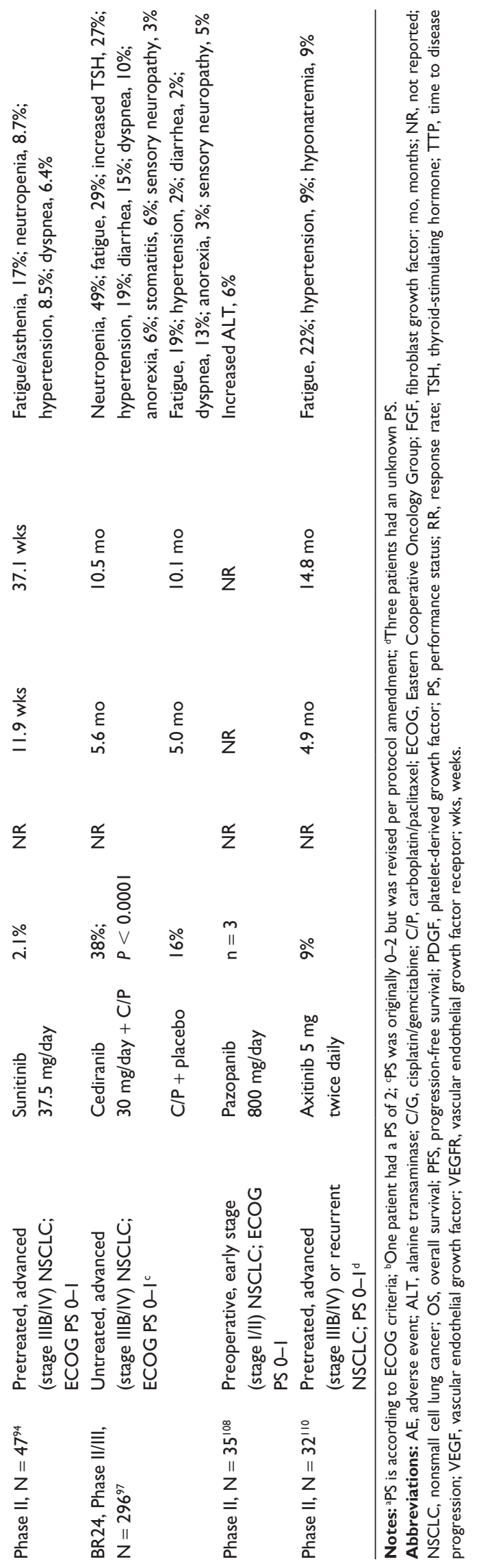

Median PFS and OS were 11.9 weeks (95\% CI, 8.6-14.1) and 37.1 weeks (95\% CI, 31.1-69.7), respectively, while the 1-year survival rate was $38.4 \%$ (95\% CI, 24.2-52.5). Common grade $\geq 3$ adverse events were fatigue or asthenia in eight patients (17\%), neutropenia in four patients $(9 \%)$, hypertension in four patients (9\%), and dyspnea in three patients $(6.4 \%)$. Sunitinib is currently being examined in a Phase II trial (CALGB 30704) as a second-line therapy in combination with pemetrexed (NCT00698815) and in a Phase III placebo-controlled trial (CALGB 30607) as a maintenance therapy after platinum-based chemotherapy in advanced NSCLC (NCT00693992).

Cediranib (AZD2171; Recentin ${ }^{\mathrm{TM}}$, AstraZeneca; Wilmington, DE) inhibits signaling through VEGFR-1, -2, and -3 , PDGFR- $\alpha / \beta$, FGFR-1, and also has activity against c-kit. ${ }^{95,96}$ Cediranib was tested as a first-line therapy in combination with carboplatin and paclitaxel in a randomized, double-blind Phase II/III trial (BR24) in 296 patients with advanced NSCLC. ${ }^{97}$ Patients with uncontrolled cardiovascular disease, severe hypertension, or hemoptysis within 4 weeks before treatment were excluded from this study. Despite initial results from the Phase II interim analysis suggesting higher ORR with cediranib (38\%) than with placebo $(16 \%, P<0.0001)$, the study was halted to review imbalances in assigned causes of death due to toxicity of the 30 -mg dose. Median PFS was not significantly improved with cediranib (5.6 months) over chemotherapy alone (5 months; HR, $0.77 ; 95 \% \mathrm{CI}, 0.56-1.08 ; P=0.13$ ), and a survival analysis update 10 months after study unblinding showed no significant advantage for cediranib over chemotherapy alone (10.5 versus 10.1 months; HR, $0.78 ; 95 \% \mathrm{CI}$, $0.57-1.06 ; P=0.11$ ). The most common grade $\geq 3$ adverse events with cediranib included neutropenia (49\%), fatigue (29\%), increased thyroid-stimulating hormone levels (27\%), hypertension (19\%), diarrhea (15\%), and dyspnea (10\%). A similar trial (BR29) is ongoing using a lower cediranib dose $(20 \mathrm{mg})$ in combination with carboplatin and paclitaxel (NCT00795340). Another ongoing Phase II trial is currently evaluating cediranib in combination with pemetrexed in previously treated patients with NSCLC of all histological subtypes, with preliminary results from the first 33 enrolled patients showing an ORR of $16 \%(90 \%$ CI, 0.08-0.30) and grade $\geq 3$ adverse events including neutropenia and fatigue, each of which was reported for seven patients. ${ }^{98}$

ABT-869 (Abbott; Abbott Park, IL) inhibits signaling through VEGFR-1, -2 , and -3 , and PDGFR- $\beta,{ }^{99,100}$ and is being tested in an open-label randomized Phase II trial of 
NSCLC patients with disease progression after previous treatment. ${ }^{101}$ An initial report on 24 patients receiving a $0.10 \mathrm{mg} / \mathrm{kg}$ daily dose and 24 patients receiving a $0.25 \mathrm{mg} / \mathrm{kg}$ daily dose showed $33 \%$ of all patients exhibited PFS of 16 weeks or longer. Median PFS was 109 and 108 days in the high- and low-dose groups, respectively. The most common grade $\geq 3$ adverse events were hypertension ( $23 \%$ in the high-dose group), hand-foot syndrome ( $8 \%$ in the high-dose group), and fatigue (7\% and $8 \%$ in the high- and low-dose groups, respectively). ${ }^{101}$

Motesanib (AMG 706; Amgen, Thousand Oaks, CA) inhibits signaling through VEGFR-1, -2 , and -3, PDGFR- $\beta$, c-kit, and RET, and inhibits VEGF-induced angiogenesis in tumor cell xenograft models. ${ }^{102}$ Motesanib is currently undergoing evaluation in patients with NSCLC in combination with chemotherapy. ${ }^{103,104}$ In an initial Phase Ib study involving 26 patients with solid tumors, grade $\geq 3$ deep vein thrombosis and neutropenia were reported in one patient each, one patient had a partial response, and seven patients achieved stable disease at 52 days (although none showed stable disease for longer than 24 weeks). ${ }^{104}$ In a subsequent Phase II study, 181 patients with advanced nonsquamous NSCLC received treatment with motesanib $125 \mathrm{mg}$ once daily or $75 \mathrm{mg}$ twice daily or bevacizumab $15 \mathrm{mg} / \mathrm{kg}$ in combination with carboplatin and paclitaxel. ${ }^{103}$ Preliminary results showed partial responses in $23 \%$ and $22 \%$ of patients in the $125 \mathrm{mg}$ and $75 \mathrm{mg}$ motesanib groups, respectively, and $29 \%$ in the bevacizumab group, while median PFS was 7.4 months (95\% CI, 5.3-8.5), 5.2 months (95\% CI, 4.2-6.8), and 6.8 months (95\% CI, 4.4-8.8) in the three treatment groups, respectively. The most common grade $\geq 3$ adverse events in the three groups were diarrhea (19\%, $13 \%$, and $3 \%$ ), dehydration $(17 \%, 8 \%$, and $3 \%$ ), fatigue $(17 \%, 5 \%$, and $8 \%)$, anorexia $(12 \%, 2 \%$, and $3 \%)$, and nausea $(10 \%, 3 \%$, and $2 \%)$. The ongoing Phase III MONET1 study (NCT00460317) was initially suspended because of a higher incidence of mortality and hemoptysis in patients with squamous NSCLC treated with motesanib plus carboplatin and paclitaxel compared with those who had nonsquamous NSCLC. The trial has since resumed with an expected enrollment of 1400 patients, but recruitment is now limited to patients who have tumors with nonsquamous histology. ${ }^{105}$

Pazopanib (GW786034; GlaxoSmithKline, London, UK) inhibits VEGFR-1, -2, and -3, FGFR-1, PDGFR- $\alpha / \beta$ signaling, and c-kit. ${ }^{106,107}$ Pazopanib as preoperative monotherapy was investigated in a Phase II trial involving 35 patients with NSCLC scheduled for resection. ${ }^{108}$ Patients with a history of hemoptysis or evidence of bleeding were excluded from the study. Of 35 patients, three had a partial response and 30 patients $(86 \%)$ showed tumor-volume reduction (two of whom had a volume reduction of $50 \%$ or more). The most common grade $\geq 3$ adverse event was an increase in serum ALT levels, reported for two patients.

Axitinib (AG-013736; Pfizer, New London, CT) targets VEGFR-1, $-2,-3$, and PDGFR- $\beta .{ }^{109}$ Axitinib was evaluated in an open-label, single-arm Phase II study of 32 patients with NSCLC after at least one prior regimen of chemotherapy. ${ }^{110}$ Patients were excluded from this study if they had a history of grade $\geq 2$ hemoptysis or brain metastases. Three patients demonstrated a partial response, giving an ORR of $9 \%$, while 10 patients (31\%) experienced stable disease for 16 weeks or longer. Median PFS was 4.9 months $(95 \% \mathrm{CI}$, 3.6-7.0 months), and median OS was 14.8 months (95\% CI, 10.7-not estimable). Common grade $\geq 3$ adverse events included fatigue in seven patients $(22 \%)$, hypertension in three patients (9\%), and hyponatremia in three patients (9\%). Phase II clinical trials are currently evaluating first-line axitinib in combination with cisplatin and pemetrexed for patients with nonsquamous advanced NSCLC (NCT00768755) or in combination with cisplatin and gemcitabine in the treatment of advanced squamous NSCLC (NCT00735904).

Aflibercept (VEGF Trap; Regeneron, Tarrytown, NY), a fusion protein made up of portions of VEGFRs and human immunoglobulin G, has also shown activity in a Phase I clinical trial of patients with advanced solid tumors. ${ }^{111}$ In a Phase II trial of patients with platinum-resistant, erlotinib-resistant adenocarcinoma of the lung, aflibercept was associated with an RR of $2 \%$, median PFS of 2.7 months, and median OS of 6.2 months among 89 evaluable patients; the most common grade $\geq 3$ adverse events included hypertension (23\%), dyspnea (21\%), and proteinuria (10\%). ${ }^{112}$ A Phase III trial is ongoing to evaluate aflibercept as second-line therapy in combination with docetaxel in patients with metastatic NSCLC (NCT00532155).

\section{Conclusion}

Challenges associated with currently approved targeted therapies in NSCLC include the development of resistance and patient eligibility, and so there is a need for more effective therapies that improve clinical benefit with minimal toxicity. Ongoing studies are evaluating new antiangiogenic treatments, with potentially promising antitumor activity suggested in Phase II studies of agents that target multiple angiogenic pathways (eg, VEGFR, PDGFR, and FGF pathways). However, while Phase III combination trials with monoclonal antibodies such as bevacizumab have been 
promising, recently completed combination trials with TKIs have been disappointing. Nonetheless, results from ongoing studies are eagerly awaited to help determine how these new antiangiogenic agents may be best used either alone or in combination with traditional chemotherapy regimens to improve outcomes in individual patients.

\section{Acknowledgments}

This work was supported by Boehringer Ingelheim Pharmaceuticals, Inc (BIPI). Writing and editorial assistance was provided by Robert Lee, $\mathrm{PhD}$, of MedErgy, which was contracted by BIPI for these services. The authors received no compensation related to the development of the manuscript. The authors meet criteria for authorship as recommended by the International Committee of Medical Journal Editors (ICMJE), were fully responsible for all content and editorial decisions, and were involved at all stages of manuscript development.

Dr Chachoua has served on the Speakers Bureau for Eli Lilly, Genentech, and Response Genetics, Inc. Dr Ballas has received past honoraria from Eli Lilly.

\section{Disclosure}

The authors report no conflicts of interest in this work.

\section{References}

1. American Cancer Society. Cancer Facts and Figures, 2010. Atlanta, GA: American Cancer Society; 2010.

2. Jemal A, Siegel R, Xu J, Ward E. Cancer statistics, 2010. CA Cancer J Clin. 2010;60:277-300.

3. National Comprehensive Cancer Network. NCCN Clinical Practice Guidelines in Oncology ${ }^{\mathrm{TM}}$. Non-Small Cell Lung Cancer. V.2.2010. Available from: http://www.nccn.org/professionals/physician_gls/PDF/ nscl.pdf. Accessed April 8, 2010.

4. Breathnach OS, Freidlin B, Conley B, et al. Twenty-two years of Phase III trials for patients with advanced non-small-cell lung cancer: sobering results. J Clin Oncol. 2001;19(6):1734-1742.

5. Carney DN. Lung cancer - time to move on from chemotherapy. NEngl J Med. 2002;346(2):126-128.

6. Park JO, Kim SW, Ahn JS, et al. Phase III trial of two versus four additional cycles in patients who are nonprogressive after two cycles of platinum-based chemotherapy in non small-cell lung cancer. J Clin Oncol. 2007;25(33):5233-5239.

7. Smith IE, O'Brien ME, Talbot DC, et al. Duration of chemotherapy in advanced non-small-cell lung cancer: a randomized trial of three versus six courses of mitomycin, vinblastine, and cisplatin. J Clin Oncol. 2001; 19(5):1336-1343.

8. von Plessen C, Bergman B, Andresen O, et al. Palliative chemotherapy beyond three courses conveys no survival or consistent quality-of-life benefits in advanced non-small-cell lung cancer. Br J Cancer. 2006; 95(8):966-973.

9. $\operatorname{Tarceva}^{\circledR}$ (erlotinib tablets) [package insert]. South San Franscisco, CA: Genentech, Inc.

10. Iressa ${ }^{\circledR}$ (gefitinib tablets) [package insert]. Wilmington, DE: AstraZeneca Pharmaceuticals LP.

11. Avastin ${ }^{\circledR}$ (bevacizumab) [package insert]. South San Francisco, CA: Genentech, Inc.; 2009.
12. Sharma SV, Bell DW, Settleman J, Haber DA. Epidermal growth factor receptor mutations in lung cancer. Nat Rev Cancer. 2007;7(3): $169-181$.

13. Cohen MH, Williams GA, Sridhara R, Chen G, Pazdur R. FDA drug approval summary: gefitinib (ZD1839) (Iressa) tablets. Oncologist. 2003;8(4):303-306.

14. Fukuoka M, Yano S, Giaccone G, et al. Multi-institutional randomized phase II trial of gefitinib for previously treated patients with advanced non-small-cell lung cancer (The IDEAL 1 Trial) [corrected]. J Clin Oncol. 2003;21(12):2237-2246.

15. Thatcher N, Chang A, Parikh P, et al. Gefitinib plus best supportive care in previously treated patients with refractory advanced nonsmall-cell lung cancer: results from a randomised, placebo-controlled, multicentre study (Iressa Survival Evaluation in Lung Cancer). Lancet. 2005;366(9496):1527-1537.

16. Giaccone G, Herbst RS, Manegold C, et al. Gefitinib in combination with gemcitabine and cisplatin in advanced non-small-cell lung cancer: a phase III trial - INTACT 1. J Clin Oncol. 2004;22(5):777-784.

17. Herbst RS, Giaccone G, Schiller JH, et al. Gefitinib in combination with paclitaxel and carboplatin in advanced non-small-cell lung cancer: a phase III trial - INTACT 2. J Clin Oncol. 2004;22(5): 785-794.

18. Gautschi O, Mack PC, Davies AM, Jablons DM, Rosell R, Gandara DR. Pharmacogenomic approaches to individualizing chemotherapy for non-small-cell lung cancer: current status and new directions. Clin Lung Cancer. 2008;9(Suppl 3):S129-S138.

19. Kim ES, Hirsh V, Mok T, et al. Gefitinib versus docetaxel in previously treated non-small-cell lung cancer (INTEREST): a randomised Phase III trial. Lancet. 2008;372(9652):1809-1818.

20. Maruyama R, Nishiwaki Y, Tamura T, et al. Phase III study, V-15-32, of gefitinib versus docetaxel in previously treated Japanese patients with non-small-cell lung cancer. J Clin Oncol. 2008;26(26):4244-4252.

21. AstraZeneca. IRESSA (Gefitinib) receives marketing authorisation for the treatment of non-small cell lung cancer in Europe. http://www. astrazeneca.com/Media/Press-releases/Article/20090701-IRESSAGefitinib-Receives-Marketing-Authorisation-f. Accessed April 8, 2010.

22. Erlotinib (Tarceva) for advanced non-small cell lung cancer. Med Lett Drugs Ther. 2005;47(1205):25-26.

23. Shepherd FA, Rodrigues PJ, Ciuleanu T, et al. Erlotinib in previously treated non-small-cell lung cancer. $N$ Engl J Med. 2005;353(2): 123-132.

24. Genentech Inc. FDA approves Tarceva as a maintenance therapy for advanced non-small cell lung cancer. http://www.gene.com/gene/news/ press-releases/display.do?method=detail\&id=12727. Accessed April 21, 2010.

25. Cappuzzo F, Ciuleanu T, Stelmakh L, et al. Erlotinib as maintenance treatment in advanced non-small-cell lung cancer: a multicentre, randomised, placebo-controlled phase 3 study. Lancet Oncol. 2010;11(6): 521-529.

26. Jackman DM, Yeap BY, Sequist LV, et al. Exon 19 deletion mutations of epidermal growth factor receptor are associated with prolonged survival in non-small cell lung cancer patients treated with gefitinib or erlotinib. Clin Cancer Res. 2006;12(13):3908-3914.

27. Mitsudomi T, Kosaka T, Endoh H, et al. Mutations of the epidermal growth factor receptor gene predict prolonged survival after gefitinib treatment in patients with non-small-cell lung cancer with postoperative recurrence. J Clin Oncol. 2005;23(11):2513-2520.

28. Riely GJ, Pao W, Pham D, et al. Clinical course of patients with nonsmall cell lung cancer and epidermal growth factor receptor exon 19 and exon 21 mutations treated with gefitinib or erlotinib. Clin Cancer Res. 2006;12(3 Pt 1):839-844.

29. Engelman JA, Janne PA. Mechanisms of acquired resistance to epidermal growth factor receptor tyrosine kinase inhibitors in non-small cell lung cancer. Clin Cancer Res. 2008;14(10):2895-2899.

30. Kerbel RS. Antiangiogenic therapy: a universal chemosensitization strategy for cancer? Science. 2006;312(5777):1171-1175. 
31. Carmeliet P. Angiogenesis in life, disease and medicine. Nature. 2005; 438(7070):932-936.

32. Kreuter M, Kropff M, Fischaleck A, et al. Prognostic relevance of angiogenesis in stage III NSCLC receiving multimodality treatment. Eur Respir J. 2009;33(6):1383-1388.

33. Meert AP, Paesmans M, Martin B, et al. The role of microvessel density on the survival of patients with lung cancer: a systematic review of the literature with meta-analysis. Br J Cancer. 2002;87(7):694-701.

34. Weidner $\mathrm{N}$. Intratumor microvessel density as a prognostic factor in cancer. Am J Pathol. 1995;147(1):9-19.

35. Avastin $^{\circledR}$ (Bevacizumab) for intravenous use [package insert]. South San Francisco, CA: Genentech, Inc.; 2008.

36. Johnson DH, Fehrenbacher L, Novotny WF, et al. Randomized Phase II trial comparing bevacizumab plus carboplatin and paclitaxel with carboplatin and paclitaxel alone in previously untreated locally advanced or metastatic non-small-cell lung cancer. J Clin Oncol. 2004; 22(11):2184-2191.

37. Hapani S, Sher A, Chu D, Wu S. Increased risk of serious hemorrhage with bevacizumab in cancer patients: a meta-analysis. Oncology. 2010; 79(1-2):27-38.

38. Sandler A, Gray R, Perry MC, et al. Paclitaxel-carboplatin alone or with bevacizumab for non-small-cell lung cancer. N Engl J Med. 2006; 355(24):2542-2550

39. Reck M, von Pawel J, Zatloukal P, et al. Phase III trial of cisplatin plus gemcitabine with either placebo or bevacizumab as first-line therapy for nonsquamous non-small-cell lung cancer: AVAiL. J Clin Oncol. 2009;27(8):1227-1234.

40. Reck M, von Pawel J, Zatloukal P, et al. Overall survival with cisplatingemcitabine and bevacizumab or placebo as first-line therapy for nonsquamous non-small-cell lung cancer: results from a randomised phase III trial (AVAiL). Ann Oncol. 2010;21(9):1804-1809.

41. Kabbinavar FF, Miller VA, Johnson BE, O'Connor PG, Soh C, Tlas I. Overall survival (OS) in ATLAS, a phase IIIb trial comparing bevacizumab (B) therapy with or without erlotinib (E) after completion of chemotherapy (chemo) with B for first-line treatment of locally advanced, recurrent, or metastatic non-small cell lung cancer (NSCLC). J Clin Oncol. 2010;28(15s): Abstract 7526.

42. Polikoff J, Hainsworth JD, Fehrenbacher L, et al. Safety of bevacizumab (Bv) therapy in combination with chemotherapy in subjects with nonsmall cell lung cancer (NSCLC) treated on ATLAS. J Clin Oncol. 2008;26(15s): Abstract 8079.

43. Hainsworth JD, Fang L, Huang JE, et al. BRIDGE: an open-label phase II trial evaluating the safety of bevacizumab + carboplatin/paclitaxel as firstline treatment for patients with advanced, previously untreated, squamous non-small cell lung cancer. J Thorac Oncol. 2011;6(1):109-114.

44. Ardizzoni A, Boni L, Tiseo M, et al. Cisplatin- versus carboplatin-based chemotherapy in first-line treatment of advanced non-small-cell lung cancer: an individual patient data meta-analysis. $J$ Natl Cancer Inst. 2007;99(11):847-857.

45. Patel JD, Hensing TA, Rademaker A, et al. Phase II study of pemetrexed and carboplatin plus bevacizumab with maintenance pemetrexed and bevacizumab as first-line therapy for nonsquamous non-small-cell lung cancer. J Clin Oncol. 2009;27(20):3284-3289.

46. Patel JD, Bonomi P, Socinski MA, et al. Treatment rationale and study design for the pointbreak study: a randomized, open-label Phase III study of pemetrexed/carboplatin/bevacizumab followed by maintenance pemetrexed/bevacizumab versus paclitaxel/carboplatin/bevacizumab followed by maintenance bevacizumab in patients with stage IIIB or IV nonsquamous non-small-cell lung cancer. Clin Lung Cancer. 2009;10(4):252-256.

47. Adjei AA, Mandrekar SJ, Dy GK, et al. Phase II trial of pemetrexed plus bevacizumab for second-line therapy of patients with advanced non-small-cell lung cancer: NCCTG and SWOG study N0426. J Clin Oncol. 2010;28(4):614-619.

48. Hicklin DJ, Ellis LM. Role of the vascular endothelial growth factor pathway in tumor growth and angiogenesis. J Clin Oncol. 2005;23(5): $1011-1027$.
49. Ferrara N, Gerber HP, LeCouter J. The biology of VEGF and its receptors. Nat Med. 2003;9(6):669-676.

50. Neufeld G, Kessler O. The semaphorins: versatile regulators of tumour progression and tumour angiogenesis. Nat Rev Cancer. 2008;8(8):632-645.

51. Jarvis A, Allerston CK, Jia H, et al. Small molecule inhibitors of the neuropilin-1 vascular endothelial growth factor A (VEGF-A) interaction. J Med Chem. 2010;53(5):2215-2226.

52. Bagri A, Tessier-Lavigne M, Watts RJ. Neuropilins in tumor biology. Clin Cancer Res. 2009;15(6):1860-1864.

53. Fukumura D, Xavier R, Sugiura T, et al. Tumor induction of VEGF promoter activity in stromal cells. Cell. 1998;94(6):715-725.

54. Gerber HP, Kowalski J, Sherman D, Eberhard DA, Ferrara N. Complete inhibition of rhabdomyosarcoma xenograft growth and neovascularization requires blockade of both tumor and host vascular endothelial growth factor. Cancer Res. 2000;60(22):6253-6258.

55. Yuan A, Yu C-J, Kuo S-H, et al. Vascular endothelial growth factor 189 mRNA isoform expression specifically correlates with tumor angiogenesis, patient survival, and postoperative relapse in non-small-cell lung cancer. J Clin Oncol. 2001;19(2):432-441.

56. Delmotte P, Martin B, Paesmans M, et al. VEGF and survival of patients with lung cancer: a systematic literature review and meta-analysis [in French]. Rev Mal Respir. 2002;19(5 Pt 1):577-584.

57. Beenken A, Mohammadi M. The FGF family: biology, pathophysiology and therapy. Nat Rev Drug Discov. 2009;8(3):235-253.

58. Presta M, Dell'Era P, Mitola S, Moroni E, Ronca R, Rusnati M. Fibroblast growth factor/fibroblast growth factor receptor system in angiogenesis. Cytokine Growth Factor Rev. 2005;16(2):159-178.

59. Murakami M, Zheng Y, Hirashima M, et al. VEGFR1 tyrosine kinase signaling promotes lymphangiogenesis as well as angiogenesis indirectly via macrophage recruitment. Arterioscler Thromb Vasc Biol. 2008;28(4):658-664.

60. Klein S, Giancotti FG, Presta M, Albelda SM, Buck CA, Rifkin DB. Basic fibroblast growth factor modulates integrin expression in microvascular endothelial cells. Mol Biol Cell. 1993;4(10):973-982.

61. Underwood PA, Bean PA, Gamble JR. Rate of endothelial expansion is controlled by cell:cell adhesion. Int J Biochem Cell Biol. 2002;34(1):55-69.

62. Rusnati M, Presta M. Fibroblast growth factors/fibroblast growth factor receptors as targets for the development of anti-angiogenesis strategies. Curr Pharm Des. 2007;13(20):2025-2044.

63. Beitz JG, Kim IS, Calabresi P, Frackelton AR Jr. Human microvascular endothelial cells express receptors for platelet-derived growth factor. Proc Natl Acad Sci U SA. 1991;88(5):2021-2025.

64. Wu E, Palmer N, Tian Z, et al. Comprehensive dissection of PDGFPDGFR signaling pathways in PDGFR genetically defined cells. PLoS One. 2008;3(11):e3794.

65. Lindahl P, Johansson BR, Leveen P, Betsholtz C. Pericyte loss and microaneurysm formation in PDGF-B-deficient mice. Science. 1997; 277(5323):242-245.

66. Abramsson A, Lindblom P, Betsholtz C. Endothelial and nonendothelial sources of PDGF-B regulate pericyte recruitment and influence vascular pattern formation in tumors. J Clin Invest. 2003;112(8):1142-1151.

67. Hellstrom M, Kalen M, Lindahl P, Abramsson A, Betsholtz C. Role of PDGF-B and PDGFR-beta in recruitment of vascular smooth muscle cells and pericytes during embryonic blood vessel formation in the mouse. Development. 1999;126(14):3047-3055.

68. Oikawa T, Onozawa C, Sakaguchi M, Morita I, Murota S. Three isoforms of platelet-derived growth factors all have the capability to induce angiogenesis in vivo. Biol Pharm Bull. 1994;17(12):1686-1688.

69. Risau W, Drexler H, Mironov V, et al. Platelet-derived growth factor is angiogenic in vivo. Growth Factors. 1992;7(4):261-266.

70. Levitzki A. PDGF receptor kinase inhibitors for the treatment of PDGF driven diseases. Cytokine Growth Factor Rev. 2004;15(4):229-235.

71. Kim KJ, Li B, Winer J, et al. Inhibition of vascular endothelial growth factor-induced angiogenesis suppresses tumour growth in vivo. Nature. 1993;362(6423):841-844. 
72. Ferrara N, Davis-Smyth T. The biology of vascular endothelial growth factor. Endocr Rev. 1997;18(1):4-25.

73. Casanovas O, Hicklin DJ, Bergers G, Hanahan D. Drug resistance by evasion of antiangiogenic targeting of VEGF signaling in late-stage pancreatic islet tumors. Cancer Cell. 2005;8(4):299-309.

74. Bergers G, Song S, Meyer-Morse N, Bergsland E, Hanahan D. Benefits of targeting both pericytes and endothelial cells in the tumor vasculature with kinase inhibitors. J Clin Invest. 2003;111(9):1287-1295.

75. Erber R, Thurnher A, Katsen AD, et al. Combined inhibition of VEGF and PDGF signaling enforces tumor vessel regression by interfering with pericyte-mediated endothelial cell survival mechanisms. FASEB J. 2004;18(2):338-340

76. Kano MR, Morishita Y, Iwata C, et al. VEGF-A and FGF-2 synergistically promote neoangiogenesis through enhancement of endogenous PDGF-B-PDGFRbeta signaling. J Cell Sci. 2005;118(Pt 16): 3759-3768.

77. Nissen LJ, Cao R, Hedlund EM, et al. Angiogenic factors FGF2 and PDGF-BB synergistically promote murine tumor neovascularization and metastasis. J Clin Invest. 2007;117(10):2766-2777.

78. Spratlin JL, Cohen RB, Eadens M, et al. Phase I pharmacologic and biologic study of ramucirumab (IMC-1121B), a fully human immunoglobulin G1 monoclonal antibody targeting the vascular endothelial growth factor receptor-2. J Clin Oncol. 2010;28(5):780-787.

79. Camidge DR, Ballas MS, Dubey S, et al. A phase II, open-label study of ramucirumab (IMC-1121B), an IgG1 fully human monoclonal antibody (MAb) targeting VEGFR-2, in combination with paclitaxel and carboplatin as first-line therapy in patients (pts) with stage IIIb/IV non-small cell lung cancer (NSCLC). J Clin Oncol. 2010;28(15s):Abstract 7588.

80. Hilberg F, Roth GJ, Krssak M, et al. BIBF 1120: triple angiokinase inhibitor with sustained receptor blockade and good antitumor efficacy. Cancer Res. 2008;68(12):4774-4782.

81. Roth GJ, Heckel A, Colbatzky F, et al. Design, synthesis, and evaluation of indolinones as triple angiokinase inhibitors and the discovery of a highly specific 6-methoxycarbonyl-substituted indolinone (BIBF 1120). J Med Chem. 2009;52(14):4466-4480.

82. Mross K, Stefanic M, Gmehling D, et al. Phase I study of the angiogenesis inhibitor BIBF 1120 in patients with advanced solid tumors. Clin Cancer Res. 2010;16(1):311-319.

83. Okamoto I, Kaneda H, Satoh T, et al. Phase I safety, pharmacokinetic, and biomarker study of BIBF 1120, an oral triple tyrosine kinase inhibitor in patients with advanced solid tumors. Mol Cancer Ther. 2010;9(10):2825-2833.

84. Ellis PM, Kaiser R, Zhao Y, Stopfer P, Gyorffy S, Hanna N. Phase I open-label study of continuous treatment with BIBF 1120, a triple angiokinase inhibitor, and pemetrexed in pretreated nonsmall cell lung cancer patients. Clin Cancer Res. 2010;16(10): 2881-2889.

85. Reck M, Kaiser R, Eschbach C, et al. A Phase II double-blind study to investigate efficacy and safety of two doses of the triple angiokinase inhibitor BIBF 1120 in patients with relapsed advanced non-small-cell lung cancer. Ann Oncol. Epub 2011 Jan 6.

86. Alimta ${ }^{\circledR}$ (pemetrexed disodium) [package insert]. Indianapolis, IN: Eli Lilly and Company; December 2009.

87. Wilhelm SM, Carter C, Tang L, et al. BAY 43-9006 exhibits broad spectrum oral antitumor activity and targets the RAF/MEK/ERK pathway and receptor tyrosine kinases involved in tumor progression and angiogenesis. Cancer Res. 2004;64(19):7099-7109.

88. Blumenschein GR Jr, Gatzemeier U, Fossella F, et al. Phase II, multicenter, uncontrolled trial of single-agent sorafenib in patients with relapsed or refractory, advanced non-small-cell lung cancer. J Clin Oncol. 2009;27(26):4274-4280.

89. Schiller JH, Lee JW, Hanna NH, Traynor AM, Carbone DP. A randomized discontinuation Phase II study of sorafenib versus placebo in patients with non-small cell lung cancer who have failed at least two prior chemotherapy regimens: E2501. J Clin Oncol. 2008;26(15S): Abstract 8014 .
90. Scagliotti G, Novello S, von Pawel J, et al. Phase III study of carboplatin and paclitaxel alone or with sorafenib in advanced non-small-cell lung cancer. J Clin Oncol. 2010;28(11):1835-1842.

91. Bayer Healthcare Pharmaceuticals Inc, Onyx Pharmaceuticals Inc. Phase 3 trial of nexavar in first-line advanced non-small cell lung cancer does not meet primary endpoint of overall survival. Press release. June 14, 2010. Available from: http://www.onyx-pharm.com/ view.cfm/685/Phase-3-Trial-of-Nexavar-in-First-Line-AdvancedNon-Small-Cell-Lung-Cancer-Does-Not-Meet-Primary-Endpointof-Overall-Survival. Accessed July 27, 2010.

92. Sun L, Liang C, Shirazian S, et al. Discovery of 5-[5-fluoro-2-oxo1,2- dihydroindol-(3Z)-ylidenemethyl]-2,4- dimethyl-1H-pyrrole3 -carboxylic acid (2-diethylaminoethyl)amide, a novel tyrosine kinase inhibitor targeting vascular endothelial and platelet-derived growth factor receptor tyrosine kinase. $J$ Med Chem. 2003;46(7): 1116-1119.

93. Socinski MA, Novello S, Brahmer JR, et al. Multicenter, Phase II trial of sunitinib in previously treated, advanced non-small-cell lung cancer. J Clin Oncol. 2008;26(4):650-656.

94. Novello S, Scagliotti GV, Rosell R, et al. Phase II study of continuous daily sunitinib dosing in patients with previously treated advanced non-small cell lung cancer. Br J Cancer. 2009;101(9): $1543-1548$

95. Nikolinakos P, Heymach JV. The tyrosine kinase inhibitor cediranib for non-small cell lung cancer and other thoracic malignancies. J Thorac Oncol. 2008;3(6 Suppl 2):S131-S134.

96. Wedge SR, Kendrew J, Hennequin LF, et al. AZD2171: a highly potent, orally bioavailable, vascular endothelial growth factor receptor-2 tyrosine kinase inhibitor for the treatment of cancer. Cancer Res. 2005;65(10):4389-4400.

97. Goss GD, Arnold A, Shepherd FA, et al. Randomized, double-blind trial of carboplatin and paclitaxel with either daily oral cediranib or placebo in advanced non-small-cell lung cancer: NCIC Clinical Trials Group BR24 study. J Clin Oncol. 2010;28(1):49-55.

98. Gadgeel SM, Wozniak A, Edelman MJ, et al. Cediranib, a VEGF receptor 1,2, and 3 inhibitor, and pemetrexed in patients (pts) with recurrent non-small cell lung cancer (NSCLC). J Clin Oncol. 2009;27(15S): Abstract e19007.

99. Albert DH, Tapang P, Magoc TJ, et al. Preclinical activity of ABT869, a multitargeted receptor tyrosine kinase inhibitor. Mol Cancer Ther. 2006;5(4):995-1006.

100. Shankar DB, Li J, Tapang P, et al. ABT-869, a multitargeted receptor tyrosine kinase inhibitor: inhibition of FLT3 phosphorylation and signaling in acute myeloid leukemia. Blood. 2007;109(8): 3400-3408.

101. Tan E, Salgia R, Besse B, et al. ABT-869 in non-small cell lung cancer (NSCLC): interim results. J Clin Oncol. 2009;27(15S): Abstract 8074.

102. Polverino A, Coxon A, Starnes C, et al. AMG 706, an oral, multikinase inhibitor that selectively targets vascular endothelial growth factor, platelet-derived growth factor, and kit receptors, potently inhibits angiogenesis and induces regression in tumor xenografts. Cancer Res. 2006;66(17):8715-8721.

103. Blumenschein GR, Kabbinavar FF, Menon H, et al. Randomized, openlabel phase II study of motesanib or bevacizumab in combination with paclitaxel and carboplatin $(\mathrm{P} / \mathrm{C})$ for advanced nonsquamous non-small cell lung cancer (NSCLC). J Clin Oncol. 2010;28(15s):7528.

104. Price TJ, Lipton L, McGreivy J, McCoy S, Sun YN, Rosenthal MA. Safety and pharmacokinetics of motesanib in combination with gemcitabine for the treatment of patients with solid tumours. Br J Cancer. 2008;99(9):1387-1394.

105. Amgen. Independent Data Monitoring Committee recommends resuming enrollment of non-squamous NSCLC patients in the motesanib MONET1 trial. http://www.amgen.com/media/media_pr_detail. jsp?year=2009\&releaseID=1255738. Accessed May 12, 2010.

106. Sloan B, Scheinfeld NS. Pazopanib, a VEGF receptor tyrosine kinase inhibitor for cancer therapy. Curr Opin Investig Drugs. 2008;9(12): 1324-1335. 
107. Kumar R, Knick VB, Rudolph SK, et al. Pharmacokinetic-pharmacodynamic correlation from mouse to human with pazopanib, a multikinase angiogenesis inhibitor with potent antitumor and antiangiogenic activity. Mol Cancer Ther. 2007;6(7):2012-2021.

108. Altorki N, Lane ME, Bauer T, et al. Phase II proof-of-concept study of pazopanib monotherapy in treatment-naive patients with stage $\mathrm{I} /$ II resectable non-small-cell lung cancer. J Clin Oncol. 2010;28(19): 3131-3137.

109. Rugo HS, Herbst RS, Liu G, et al. Phase I trial of the oral antiangiogenesis agent AG-013736 in patients with advanced solid tumors: pharmacokinetic and clinical results. J Clin Oncol. 2005;23(24): 5474-5483.

110. Schiller JH, Larson T, Ou SH, et al. Efficacy and safety of axitinib in patients with advanced non-small-cell lung cancer: results from a Phase II study. J Clin Oncol. 2009;27(23):3836-3841.
111. Lockhart AC, Rothenberg ML, Dupont J, et al. Phase I study of intravenous vascular endothelial growth factor trap, aflibercept, in patients with advanced solid tumors. J Clin Oncol. 2010;28(2): 207-214.

112. Leighl NB, Raez LE, Besse B, et al. A multicenter, phase 2 study of vascular endothelial growth factor trap (Aflibercept) in platinum- and erlotinib-resistant adenocarcinoma of the lung. J Thorac Oncol. 2010; 5(7):1054-1059.

113. Ivy SP, Wick JY, Kaufman BM. An overview of small-molecule inhibitors of VEGFR signaling. Nat Rev Clin Oncol. 2009;6(10):569-579.

114. Lababede O, Meziane M, Rice T. Seventh edition of the cancer staging manual and stage grouping of lung cancer: quick reference chart and diagrams. Chest. 2011;139(1):183-189.
OncoTargets and Therapy

\section{Publish your work in this journal}

OncoTargets and Therapy is an international, peer-reviewed, open access journal focusing on the pathological basis of all cancers, potential targets for therapy and treatment protocols employed to improve the management of cancer patients. The journal also focuses on the impact of management programs and new therapeutic agents and protocols on

\section{Dovepress}

patient perspectives such as quality of life, adherence and satisfaction. The manuscript management system is completely online and includes a very quick and fair peer-review system, which is all easy to use. Visit http://www.dovepress.com/testimonials.php to read real quotes from published authors. 